\title{
An Analysis of Needs for Forest Therapy Programs for Subfertile Women
}

\author{
Seo-Yun $\mathrm{Bu}^{1}$ and Chang-Seob Shin ${ }^{2 *}$ \\ ${ }^{1}$ Graduate Department of Forest Therapy, Chungbuk National University, Cheongju 28644, Korea \\ ${ }^{2}$ Department of Forestry, Chungbuk National University, Cheongju 28644, Korea
}

\section{ABSTRACT}

The purpose of this study was to investigate 199 subfertile women 's interest in and needs for forest therapy programs according to their demographic characteristics in a subfertile clinic in Seoul to provide basic data. The results of this study were summarized as follows. First, the perception and experience of subfertile women about forest therapy were all low, but their intention to participate was generally positive. Second, the type of forest therapy preferred by subfertile women was a half-day small group that they can participate with their spouse during weekends. Third, subfertile women expected phytoncide (35.8\%) and a high level of oxygen (29.9\%) from forest therapy programs. Fourth, subfertile women expected physical and mental health such as improved blood circulation and immunity, and meditation opportunity from forest therapy. Fifth, subfertile women expected from forest therapists understanding and sympathy (62.2\%). This study conducted a survey on 199 subfertile women only. Through follow-up studies that involve more subfertile subjects and a broader region, it will be possible to develop more effective forest therapy programs for promoting the physical and mental health of subfertile subjects.

Keywords: basic data, forest therapy factors, mental and physical health

\section{Introduction}

The number of women who were diagnosed with subfertility has steadily increased over the past decade in South Korea, and the number of subfertile couples has reached at least 600,000 today (Hwang et al., 2015). As subfertility has been recognized as a serious social issue, the government introduced the Program for Supporting Subfertile Couples as a childbirth incentive in 2006, and has supported medical expenses for assisted reproductive procedures. In addition, procedures for subfertility that used to be non-payment items including artificial insemination and external fertilization started to be covered from July, 2019.

However, most of the support programs that are currently available for subfertile couples focus on financial support for 'medical procedures' only, and many studies pointed out that other types of difficulties and hardships that subfertile women experience in reality from physical, psychological, relational and cognitive perspectives have been overlooked (Devine, 2003; Hwang, 2011; Miles, 2005; Peterson et al., 2007; Yong et al., 2000). It has been reported that subfertile women experience various physical symptoms such as sleep disorders, loss of appetite, headache and chronic fatigue, and other issues such as a sense of guilt, self-degradation, a sense of inferiority, anxiety, a high level of stress from subfertility and depression, and another study pointed out that the level of stress that subfertile women experience is similar to that of cancer patients (Domar et al., 1993). Subfertile women also have psychological issues associated with becoming a mother,

Received: June 22, 2019, Revised: July 15, 2019, Accepted: August 6, 2019

First author: Seo-Yun Bu, byh627@gmail.com, (1) https://orcid.org/0000-0003-0179-6808

*Corresponding author: Chang-Seob Shin, sinna@chungbuk.ac.kr, (10) https://orcid.org/0000-0002-6298-1487 
womanhood, a sense of loss, sadness and relational problems (Lindsey and Driskill, 2013), and experience stress from procedures, a sense of control, being branded as a woman who are unable to give birth and difficulties in performing adulthood development tasks. It was reported that stress from subfertility reduces pregnancy rates, and is associated with discontinuing subfertility treatment (Cousineau and Domar, 2007).

Forest therapy is a method of feeling physical and mental comfort in a stressful life (Kim, 2006; Yoo and Jeong, 2009) through connections with the vitality of nature (Maller et al., 2006) by utilizing factors of forest therapy (Kim, 2006; Park, 2010; Yoo and Jeong, 2009). It means a series of activities led by forest therapy instructors (Kim, 2015) that improve immunity, prevent diseases and promote health by improving, maintaining and restoring quality of life from mental, social, physical, cognitive and spiritual perspectives (Park, 2010). When people are nervous under stress, the sympathetic nervous system is activated and induces negative feelings. When such situations last longer, cardiovascular diseases are easily caused and immunity is reduced. It was recently reported that slow activities such as walking in forest and forest experiences were effective for reducing tension and calling attention (Woo, 2014) and that the brainwaves, blood pressure and pulse of the body are relaxed and stabilized, and stress is reduced after a forest bath (Lee and Lee, 2013). Spending time in natural spaces like forests itself is also known to reduce physiological stress (Chang and Chen, 2005; Hartig et al., 1991; Ulrich et al., 1991; van Den Berg and Custers, 2011), and activities such as looking at surrounding landscapes in forest or walking along forest trails are known to make people subjectively feel a sense of relaxation and activate the functions of the parasympathetic nervous system (Tsunetsugu et al., 2007). Another study also reported that the higher the percentage of looking at green colors, the higher resilience from stress (Lee, 2007). These results indicate that the therapeutic effects of forest therapy can be utilized to address various difficulties that subfertile women experience from physical, psychological, emotional, cognitive and social perspectives such as stress and depression.

Customized activities for forest therapy programs need to be developed in the planning stage through a thorough analysis of participants (Lee and Kim, 2011; Seok and An, 2013). There are several earlier studies that analyzed consumers' needs for forest therapy for developing forest therapy programs such as analysis of people's interest in and needs for the development of forest therapy programs for adults (Kim et al., 2014) and analysis of urban forest users (Park and Koo, 2018). However, there has been only few studies on forest therapy programs for subfertile women. This study aimed to analyze the needs of subfertile women who came to a fertility clinic in Seoul for forest therapy programs depending on their demographic characteristics, and to provide basic data for developing and executing forest therapy programs for the promotion of the physical and mental health of subfertile women.

\section{Research Methods}

\section{Subjects and methods}

A written questionnaire survey was conducted in a fertility clinic in Seoul for 19 days from January 21, 2019 to February 8, 2019. Subjects were selected using a convenience sampling method. Researchers visited the clinic, and explained the purpose of this study to women who were waiting for diagnosis of and treatment for subfertility. Questionnaire sheets were distributed to those who agreed to participate in this study and were collected on the spot. A total of 210 questionnaire sheets were collected, and 11 sheets that did not sufficiently answer were excluded. As a result, a total of 199 sheets were analyzed.

\section{Composition of questionnaire questions about needs for programs}

In order to survey subfertile women's needs for forest therapy programs in Korea, a questionnaire composed of a total of 31 questions was developed using the content of questionnaires used in related studies in Korea (Kang, 2015; Kim, 2015; Kim et al., 2011) as follows: 12 questions on the demographic characteristics of subfertile women; one question on awareness of forest therapy; two questions on experience of forest therapy programs; four questions 
Table 1. Survey contents

\begin{tabular}{|c|c|c|c|}
\hline Contents & & Category & $\begin{array}{c}\text { Number of } \\
\text { questions }\end{array}$ \\
\hline Demographic & \multicolumn{2}{|c|}{$\begin{array}{l}\text { Age, spouse age, marriage duration, education, spouse education, occupation, spouse occupation, } \\
\text { monthly income, religion, family member living together }\end{array}$} & 12 \\
\hline \multirow{5}{*}{$\begin{array}{l}\text { Forest therapy program } \\
\text { for subfertile women }\end{array}$} & Awareness of forest therapy & 1. Knowledge about forest therapy & 19 \\
\hline & $\begin{array}{l}\text { Experience of participation in } \\
\text { forest therapy program }\end{array}$ & $\begin{array}{l}\text { 2. Experience of participation in forest therapy programs } \\
\text { 3. Frequency of visiting forests }\end{array}$ & \\
\hline & $\begin{array}{l}\text { Intention to participate in forest } \\
\text { therapy program }\end{array}$ & $\begin{array}{l}\text { 4. Desire for forest therapy program participation } \\
\text { 5. Reasons for not participating in forest therapy program } \\
\text { 6. Appropriate number of forest therapy program participants } \\
\text { 7. Companion of participation in forest therapy program }\end{array}$ & \\
\hline & $\begin{array}{l}\text { Preference for forest therapy } \\
\text { programs }\end{array}$ & $\begin{array}{l}\text { 8. Duration of forest therapy program } \\
\text { 9. Preferred day of forest therapy program } \\
\text { 10. Need for a forest therapy program for couples } \\
\text { 11. Duration of therapy program for infertile couples } \\
\text { 12. Qualifications for the forest therapists } \\
\text { 13. Preferred forest type } \\
\text { 14. Preferred forest location } \\
\text { 15. Preferred forest program space }\end{array}$ & \\
\hline & Purpose of participation & $\begin{array}{l}\text { 16. Forest factors to help } \\
\text { 17. Physical effects of forest therapy } \\
\text { 18. Psychological effects of forest therapy } \\
\text { 19. Self-help group effects of forest therapy }\end{array}$ & \\
\hline \multicolumn{3}{|r|}{ Total } & 31 \\
\hline
\end{tabular}

on intention to participate in forest therapy programs; eight questions on preference for forest therapy programs; and four questions on purpose of participation (Table 1). This questionnaire was reviewed by one subfertility counselor and one forest therapist.

\section{Data analysis}

Data collected in this study were analyzed using SPSS 21.0 for window (SPSS Inc., Chicago, Illinois, USA), and the demographic characteristics of subjects were analyzed using frequency analysis. Cross tabulation analysis was conducted to analyze subfertile women's needs for forest therapy programs depending on their demographic characteristics.

\section{Results and Discussion}

\section{Demographic characteristics}

The demographic characteristics of subjects are as shown in Table 2. They had an experience of subfertility treatment, and had no child. Their age ranged from 23 to 50, and the number of those aged between 35 and 39 was the highest $(79,39.7 \%)$, followed by those aged between 30 and $34(58,29.1 \%)$ and those aged over $40(55,27.6 \%)$. The number of those whose spouses were aged over 40 was $86(43.2 \%)$, and that of those aged between 35 and 39 was $73(36.7 \%)$. The number of those who were married for 5-10 years was the highest $(52,26.1 \%)$, followed by $3-5$ years $(51,25.6 \%)$, and 1-2 years $(37,18.6 \%)$. In terms of academic background, the number of university graduates was the highest $(116,58.3 \%)$, followed by high school graduates or lower $(27,13.6 \%)$, and graduate school and 2-year college graduates $(28,14.1 \%)$ respectively. The number of their spouses who were university graduates was the highest $(123,61.8 \%)$, followed by graduate school graduates $(27,13.6 \%)$, high school graduates or lower $(26$, $13.1 \%)$, and 2-year college graduates $(23,11.6 \%)$. In terms of occupation, the number of housewives was the highest $(74,37.2 \%)$, followed by professional workers $(47,23.6 \%)$, 
Table 2. Demographic characteristics of respondents $(N=199)$

\begin{tabular}{|c|c|c|c|}
\hline Variable & Category & $\mathrm{n}$ & $\%$ \\
\hline \multirow[t]{4}{*}{ Age } & $20-29$ years & 7 & 3.5 \\
\hline & $30-34$ years & 58 & 29.1 \\
\hline & $35-39$ years & 79 & 39.7 \\
\hline & Over 40 & 55 & 27.6 \\
\hline \multirow[t]{4}{*}{ Age of spouse } & $20-29$ years & 4 & 2.0 \\
\hline & $30-34$ years & 36 & 18.1 \\
\hline & $35-39$ years & 73 & 36.7 \\
\hline & Over 40 & 86 & 43.2 \\
\hline \multirow[t]{6}{*}{ Marriage duration } & Less than 1 year & 9 & 4.5 \\
\hline & $1-2$ years & 37 & 18.6 \\
\hline & $2-3$ years & 36 & 18.1 \\
\hline & $3-5$ years & 51 & 25.6 \\
\hline & $5-10$ years & 52 & 26.1 \\
\hline & More than 10 years & 14 & 7.0 \\
\hline \multirow[t]{4}{*}{ Education } & High school graduate & 27 & 13.6 \\
\hline & 2-year college graduate & 28 & 14.1 \\
\hline & College graduates & 116 & 58.3 \\
\hline & Graduate school & 28 & 14.1 \\
\hline \multirow[t]{4}{*}{ Education of spouse } & High school graduate or lower & 26 & 13.1 \\
\hline & 2-year college graduate & 23 & 11.6 \\
\hline & College graduate & 123 & 61.8 \\
\hline & Graduate school & 27 & 13.6 \\
\hline \multirow[t]{6}{*}{ Occupation } & Housewife & 74 & 37.2 \\
\hline & Service & 15 & 7.5 \\
\hline & Office work & 45 & 22.6 \\
\hline & Self-employed / Sales & 10 & 5.0 \\
\hline & Technical & 8 & 4.0 \\
\hline & Profession & 47 & 23.6 \\
\hline \multirow[t]{6}{*}{ Occupation of spouse } & Unemployed & 3 & 1.5 \\
\hline & Service & 9 & 4.5 \\
\hline & Office work & 69 & 34.7 \\
\hline & Self-employed / Sales & 32 & 16.1 \\
\hline & Technical & 30 & 15.1 \\
\hline & Profession & 56 & 28.1 \\
\hline \multirow[t]{5}{*}{ Total monthly income (KRW) } & Less than $2,000,000$ & 7 & 3.5 \\
\hline & $2.001,000-3,000,000$ & 20 & 10.1 \\
\hline & $3.001,000-4,000,000$ & 29 & 14.6 \\
\hline & $4.001,000-4,000,000$ & 42 & 21.1 \\
\hline & More than $5,000,000$ & 101 & 50.8 \\
\hline \multirow[t]{5}{*}{ Religion } & None & 90 & 45.2 \\
\hline & Christian & 49 & 24.6 \\
\hline & Catholic & 29 & 14.6 \\
\hline & Buddhism & 28 & 14.1 \\
\hline & Others & 3 & 1.5 \\
\hline
\end{tabular}


Table 2. (continued)

\begin{tabular}{|c|c|c|c|}
\hline Variable & Category & $\mathrm{n}$ & $\%$ \\
\hline \multirow[t]{4}{*}{ Family member living together } & Spouse only & 191 & 96.0 \\
\hline & Parents & 6 & 3 \\
\hline & Parents-in-law & 1 & 0.5 \\
\hline & Spouse's sibling & 1 & 0.5 \\
\hline \multirow[t]{4}{*}{ The spouse's birth order among brothers } & First & 92 & 46.2 \\
\hline & Second or more & 38 & 19.1 \\
\hline & Youngest & 51 & 25.6 \\
\hline & Only-child & 18 & 9.0 \\
\hline \multirow[t]{7}{*}{ Residence } & Seoul & 144 & 72.4 \\
\hline & Gyeonggi-do & 37 & 18.6 \\
\hline & Chungcheong-do & 4 & 2.0 \\
\hline & Kyongsang-do & 8 & 4.0 \\
\hline & Jeolla-do & 4 & 2.0 \\
\hline & Gangwon-do & 2 & 1.0 \\
\hline & Jeju-do & 2 & 1 \\
\hline
\end{tabular}

office workers, service workers, self-employed/sales workers and technical workers. The number of those whose spouses were office workers was the highest $(69,34.7 \%)$, followed by professional workers $(56,28.1 \%)$, self-employed/sales workers $(32,16.1 \%)$, technical workers $(30$, $15.1 \%)$, service workers $(9,4.5 \%)$, and unemployed $(3,1.5 \%)$. The number of those whose monthly family income was over $5,001,000$ won or higher was the highest $(101,50.8 \%)$, followed by 4,001,000-5,000,000 won (42, 21.1\%), 3,001,000$4,000,000$ won $(29,14.6 \%), 2,001,000-3,000,000$ won (20, $10.1 \%$ ), and 2,000,000 won or lower $(7,3.5 \%)$. In terms of religion, the number of those who had no religion was the highest (90, 45.2\%), followed by Christianity, Catholicism, Buddhism and others. Most of the subjects were surveyed to live with their spouse $(191,96.0 \%)$. The birth order of their spouses among brothers was also surveyed, and the number of those who were the first child was the highest (92, 46.2\%) and 18 spouses $(9.0 \%)$ were an only-child. The number of those who lived in Seoul was the highest (144, 72.4\%), followed by Gyeonggi-do, Gyeongsang-do, Chungcheong-do and Jeolla-do and Gangwon-do.

\section{Analysis of subfertile women's needs for forest therapy programs depending on their demographic characteristics}

\section{Awareness and experience of forest therapy}

Subfertile women's awareness of forest therapy was surveyed, and the majority of the surveyed women were not aware of forest therapy (75.4\%), and $24.6 \%$ answered that they heard about forest therapy (Table 3). In addition, 96.5\% answered that they had no experience of forest therapy programs, which was partially different from the results of Kim (2015) that analyzed people's interest in and needs for forest therapy programs for adults and those of Park and Koo (2018) that analyzed people's needs for developing forest therapy programs that utilize urban forests. The two earlier studies reported that people's awareness of forest therapy was high while the number of those who had experience was low. In this study, however, subfertile women were found to be less aware and have less experience of forest therapy. Park (1993) reported that emotional depression that subfertile women experienced gradually led to isolation from social relations including marital relations, family members, friends and neighbors. These results seem to be associated with their very low exposure to information on forest therapy programs. This increases the necessity for pro- 
moting the effects of forest therapy in a more active manner by targeting subfertile women considering their withdrawn emotional and socio-relational conditions. Table 4 shows their awareness by age group, and $32.7 \%$ of those aged over 40 answered that they heard about forest therapy. The percentage of those aged between 30 and 34 was the lowest $(12.1 \%, p=.043)$

\section{Frequency of visiting forests}

The frequency of visiting forests was surveyed (Table 5), and $47.7 \%$ answered that they hardly visited forests. Visiting forests more than once a year was $20.6 \%$, followed by more than once a quarter $(17.6 \%)$, more than once a month $(8.5 \%)$, and more than once a week (5.5\%) (Table 3). By academic background, $59.3 \%$ of high school graduates, $82.1 \%$ of 2-year college graduates, $36.2 \%$ of university graduates, and $50.0 \%$ of graduate school graduates answered that they hardly visited forests, and $11.1 \%$ of high school graduates, $3.6 \%$ of 2-year college graduates, $4.3 \%$ of university graduates, and $7.1 \%$ of graduate school graduates answered that they visited forests more than once a week. In addition, $3.7 \%$ of high school graduates, $3.6 \%$ of 2 -year college

Table 3. Forest therapy program awareness and participation of subfertile women $(N=199)$

\begin{tabular}{|c|c|c|c|}
\hline Variable & Category & $\mathrm{n}$ & $\%$ \\
\hline \multirow[t]{2}{*}{ Awareness of forest therapy } & Known & 49 & 24.6 \\
\hline & Not known & 150 & 75.4 \\
\hline \multirow[t]{2}{*}{ Participation experience of forest therapy program } & Some & 7 & 3.5 \\
\hline & None & 192 & 96.5 \\
\hline \multirow[t]{5}{*}{ Frequency of visiting forests } & More than once a week & 11 & 5.5 \\
\hline & More than once a month & 17 & 8.5 \\
\hline & More than once a quarter & 35 & 17.6 \\
\hline & More than once a year & 41 & 20.6 \\
\hline & None & 95 & 47.7 \\
\hline \multirow[t]{5}{*}{ Desire for forest therapy program participation } & Strongly agree & 20 & 10.1 \\
\hline & Slightly agree & 53 & 26.6 \\
\hline & Neutral & 79 & 39.7 \\
\hline & Slightly disagree & 38 & 19.1 \\
\hline & Strongly disagree & 9 & 4.5 \\
\hline \multirow[t]{5}{*}{ Reasons for not participating in forest therapy program } & Busy & 122 & 61.3 \\
\hline & Cost & 11 & 5.5 \\
\hline & Unwilling & 38 & 19.1 \\
\hline & Weakness of body & 3 & 1.5 \\
\hline & Unhelpful & 25 & 12.6 \\
\hline
\end{tabular}

Table 4. Forest therapy program awareness in subfertile women by age

\begin{tabular}{ccccc}
\hline Category & \multicolumn{3}{c}{ Frequency $(\%)$} & \multirow{2}{*}{$\chi^{2}(p)$} \\
\cline { 2 - 4 } & Known & Not known & $7(100.0)$ \\
20-29 years & $1(14.3)$ & $6(85.7)$ & $58(100.0)$ & 8.133 \\
$30-34$ years & $7(12.1)$ & $51(87.9)$ & $79(100.0)$ & $\left(.043^{*}\right)$ \\
Over 40 years & $23(29.1)$ & $56(70.9)$ & $55(100.0)$ & \\
Total & $18(32.7)$ & $37(67.3)$ & $199(100.0)$ & \\
\hline
\end{tabular}

${ }^{*} p<.05$ by Chi square test. 
graduates, $10.3 \%$ of university graduates, and $10.7 \%$ of graduate school graduates answered that they visited forests more than once a month, and $18.5 \%$ of high school graduates, $7.1 \%$ of 2 -year college graduates, $21.6 \%$ of university graduates, and $10.7 \%$ of graduate school graduates answered that they visited forests more than once a quarter. It was found that $7.4 \%$ of high school graduates, $3.6 \%$ of 2-year college graduates, $27.6 \%$ of university graduates, and $21.4 \%$ of graduate school graduates visited forests more than once a year $(p=.063)$.

\section{Intention to participate in forest therapy programs for subfertile women and reasons for nonparticipation}

To the question about intention to participate in forest therapy programs for subfertile women, the number of those who answered neutral was the highest (39.7\%), followed by agree $(26.6 \%)$ and strongly agree $(10.1 \%)$, which indicates that most of the subjects showed positive intentions (Table 3). To the question about reasons for nonparticipation, the number of those who answered that they had no time was the highest $(61.3 \%)$, followed by trouble- some $(19.1 \%)$, and the results differed depending on the academic background of respondents (Table 6). To the question, $23.1 \%$ of high school graduates or lower picked financial reasons, and $78.3 \%$ of college graduates, $59.3 \%$ of university graduates, and $70.4 \%$ of graduate school graduates answered that they had no time $(p=.008)$.

\section{Desired number of participants in forest therapy programs for subfertile women}

The number of those who answered that the desired number of participants in forest therapy programs for subfertile women was $2-5(46.7 \%)$, followed by $6-10(45.2 \%)$ (Table 7). These results coincided with the results of Kim (2015) that analyzed needs for developing forest therapy programs.

\section{Desired persons to participate in forest therapy programs with}

To the question about persons who subjects desired to participate in programs with, the number of those who answered their spouse was the highest $(70.4 \%)$, followed by

Table 5. Frequency of visiting forests in subfertile women by education

\begin{tabular}{lccccccc}
\hline \multirow{2}{*}{ Category } & \multicolumn{7}{c}{ Frequency $(\%)$} \\
\cline { 2 - 6 } & $\begin{array}{c}\text { More than } \\
\text { once a week }\end{array}$ & $\begin{array}{c}\text { More than } \\
\text { once a month }\end{array}$ & $\begin{array}{c}\text { More than } \\
\text { once a quarter }\end{array}$ & $\begin{array}{c}\text { More than } \\
\text { once a year }\end{array}$ & None & Total & $\chi^{2}(p)$ \\
\hline High school graduate & $3(11.1)$ & $1(3.7)$ & $5(18.5)$ & $2(7.4)$ & $16(59.3)$ & $27(100.0)$ \\
2-year college graduate & $1(3.6)$ & $1(3.6)$ & $2(7.1)$ & $1(3.6)$ & $23(82.1)$ & $28(100.0)$ & 27.777 \\
College graduate & $5(4.3)$ & $12(10.3)$ & $25(21.6)$ & $32(27.6)$ & $42(36.2)$ & $116(100.0)$ & $\left(.006^{* *}\right)$ \\
Graduate school & $2(7.1)$ & $3(10.7)$ & $3(10.7)$ & $6(21.4)$ & $14(50.0)$ & $28(100.0)$ & $199(100.0)$ \\
Total & $11(5.5)$ & $17(8.5)$ & $35(17.6)$ & $41(20.6)$ & $95(47.7)$ & \\
\hline
\end{tabular}

$* * p<.01$ by Chi square test.

Table 6. Reasons for nonparticipation in forest therapy program in subfertile women by education

\begin{tabular}{lccccccc}
\hline \multirow{2}{*}{ Category } & \multicolumn{7}{c}{ Frequency $(\%)$} \\
\cline { 2 - 6 } & Busy & Cost & Unwilling & Weakness & Unhelpful & Total & $\chi^{2}(p)$ \\
\hline High school graduate & $12(16.2)$ & $6(23.1)$ & $4(15.4)$ & $1(3.8)$ & $3(11.5)$ & $26(100.0)$ \\
2-year college graduate & $18(78.3)$ & $0(0)$ & $2(8.7)$ & $0(0)$ & $3(13.0)$ & $23(100.0)$ & 26.794 \\
College graduate & $73(59.3)$ & $5(4.1)$ & $26(21.1)$ & $1(0.8)$ & $18(14.6)$ & $123(100.0)$ & $\left(.008^{* *}\right)$ \\
Graduate school & $19(70.4)$ & $0(0)$ & $6(22.2)$ & $1(3.7)$ & $1(3.7)$ & $27(100.0)$ & $199(100.0)$ \\
Total & $122(61.3)$ & $11(5.5)$ & $38(19.1)$ & $3(1.5)$ & $26(12.6)$ & \\
\hline
\end{tabular}

${ }^{* *} p<.01$ by Chi square test. 
Table 7. Desired forest therapy program requirements for subfertile women $(N=199)$

\begin{tabular}{|c|c|c|c|}
\hline Variable & Category & $\mathrm{n}$ & $\%$ \\
\hline \multirow{5}{*}{$\begin{array}{l}\text { Reasonable number of participants in forest } \\
\text { therapy program }\end{array}$} & 1 person & 5 & 2.5 \\
\hline & 2-5 people & 93 & 46.7 \\
\hline & 6-10 people & 90 & 45.2 \\
\hline & 11-15 people & 10 & 5.0 \\
\hline & 15 or more & 1 & 0.5 \\
\hline \multirow{4}{*}{$\begin{array}{l}\text { Companion of participants in forest therapy } \\
\text { program }\end{array}$} & Spouse & 140 & 70.4 \\
\hline & Friends & 6 & 3.0 \\
\hline & Subfertile women & 33 & 16.6 \\
\hline & Alone & 20 & 10.1 \\
\hline \multirow{6}{*}{$\begin{array}{l}\text { Duration of forest therapy program for } \\
\text { subfertile women }\end{array}$} & Once a week, 120 minutes per session, total 8 sessions & 123 & 61.8 \\
\hline & once a week, 120 minutes per session, total 12 sessions & 45 & 22.6 \\
\hline & Once a week, 180 minutes per session, total 12 sessions & 5 & 2.5 \\
\hline & Twice a week, 120 minutes per session, total 16 sessions & 7 & 3.5 \\
\hline & Twice a week, 180 minutes per session, total 16 sessions & 2 & 1.0 \\
\hline & Other & 17 & 8.5 \\
\hline \multirow[t]{4}{*}{ Preferred day of forest therapy program } & Weekdays & 38 & 19.1 \\
\hline & Saturdays & 84 & 42.2 \\
\hline & Sundays & 107 & 54.9 \\
\hline & Any time & 46 & 23.1 \\
\hline \multirow{2}{*}{$\begin{array}{l}\text { Need of forest therapy program for } \\
\text { subfertile couples }\end{array}$} & Yes & 92 & 46.2 \\
\hline & No & 107 & 53.8 \\
\hline \multirow{7}{*}{$\begin{array}{l}\text { Duration of forest therapy program for } \\
\text { subfertile couples }\end{array}$} & Half day (morning or afternoon) & 77 & 38.7 \\
\hline & A day & 39 & 19.6 \\
\hline & 1 night 2 days & 29 & 14.6 \\
\hline & 2 nights 3 days & 2 & 1.0 \\
\hline & 3 nights 4 days & 1 & 0.5 \\
\hline & Within a week & 2 & 1.0 \\
\hline & No answer & 49 & 24.6 \\
\hline
\end{tabular}

acquaintances who experienced subfertility (16.6\%), alone (10.1\%), and friends (3.0\%) (Table 7). These results were similar to the results of Kim (2015) and Park and Koo (2018) that the number of subjects who answered family members was the highest. The results differed depending on the monthly family income and family members who subjects lived together with (Table 8). Out of those whose monthly family income was less than 2 million won, $28.6 \%$ answered that they wanted to participate with friends, and $65.0 \%$ of those whose monthly family income was $2,001,000-3,000,000$ won answered their spouse. It was also found that $69.0 \%$ of those whose monthly family income was $3,001,000-4,000,000$ won, $64.3 \%$ of those whose monthly family income was 4,001,000-5,000,000 won, and $74.3 \%$ of those whose monthly family income was over $5,000,000$ won answered their spouse $(p=.019)$. Out of those who lived with their spouse only, $72.3 \%$ answered they wanted to participate with their spouse, and $33.3 \%$ of those who lived with their parents together wanted to participate with their spouse or acquaintances respectively. It was found that $100 \%$ of those who lived with their parents-in-law answered that they wanted to participate alone, and that $100 \%$ of those who lived with their spouse's siblings answered that they wanted to participate with acquaintances. 
Table 8. Desired subfertile women's companion in forest therapy program by income and family member living together

\begin{tabular}{|c|c|c|c|c|c|c|}
\hline \multirow{2}{*}{ Category } & \multicolumn{5}{|c|}{ Frequency $(\%)$} & \multirow{2}{*}{$\chi^{2}(p)$} \\
\hline & Spouse & Friend & Acquaintance & Alone & Total & \\
\hline \multicolumn{7}{|c|}{ Total monthly income (KRW) } \\
\hline $2,000,000$ or less & $5(71.4)$ & $2(28.6)$ & $0(0)$ & $0(0)$ & $7(100.0)$ & \multirow{6}{*}{$\begin{array}{l}24.138 \\
\left(.019^{*}\right)\end{array}$} \\
\hline $2,001,000-3,000,000$ & $13(65.0)$ & $0(0)$ & $3(15.0)$ & $4(20.0)$ & $20(100.0)$ & \\
\hline $3,001,000-4,000,000$ & $20(69.0)$ & $1(3.4)$ & $4(13.8)$ & $4(13.8)$ & $29(100.0)$ & \\
\hline $4,001,000-5,000,000$ & $27(64.3)$ & $1(2.4)$ & $11(26.2)$ & $3(7.1)$ & $42(100.0)$ & \\
\hline Over $5,000,000$ & $75(74.3)$ & $2(2.0)$ & $15(14.9)$ & $9(8.9)$ & $101(100.0)$ & \\
\hline Total & $140(70.4)$ & $6(3.0)$ & $33(16.6)$ & $20(10.1)$ & $199(100.0)$ & \\
\hline \multicolumn{7}{|c|}{ Family member living together } \\
\hline Spouse only & $138(72.3)$ & $5(2.6)$ & $30(15.7)$ & $18(9.4)$ & $1919(100.0)$ & \multirow{4}{*}{$\begin{array}{l}20.495 \\
\left(.015^{*}\right)\end{array}$} \\
\hline Parents & $2(33.3)$ & 1(16.7) & $2(33.3)$ & $1(16.7)$ & $6(100.0)$ & \\
\hline Parents-in-law & $0(0)$ & $0(0)$ & $0(0)$ & $1(100.0)$ & $1(100.0)$ & \\
\hline Spouse's sibling & $0(0)$ & $0(0)$ & $1(100.0)$ & $0(0)$ & $1(100.0)$ & \\
\hline Total & $140(70.4)$ & $6(3.0)$ & $33(16.6)$ & $20(10.1)$ & $199(100.0)$ & \\
\hline
\end{tabular}

$* p<.05$ by Chi square test.

\section{Desired day of the week and operation schedule of forest therapy programs}

The day of the week that subfertile women preferred was Sunday (54.9\%), Saturday (42.2\%), and any day either weekday or weekend $(23.1 \%$, Table 7$)$. To the question about the operation schedule of forest therapy programs, the number of those who answered once a week, $120 \mathrm{mi}-$ nutes per session, a total of 8 sessions was the highest (61.8\%), followed by once a week, 120 minutes per session, a total of 12 sessions (22.6\%). These results were similar to the results of Park and Koo (2018) that the number of subjects who answered 1 3 hours for forest therapy programs was high. The preferred number of sessions differed depending on religion and residence (Table 9). First, 64.4\% of those who had no religion answered that they wanted once a week, 120 minutes per session, a total of 8 sessions, and $55.1 \%$ of those who were christian, $62.1 \%$ of those who were catholic, $64.3 \%$ of those who were Buddhist, and $66.7 \%$ of those who had other religions answered once a week, 120 minutes per session, a total of 8 sessions. Regardless of religion, the number of respondents who wanted to participate once a week, 120 minutes per session, a total of 8 sessions was the highest, and this result can be reflected when determining the number of sessions or hours in the process of designing programs. In terms of residence, $60.4 \%$ of those who lived in Seoul, $67.6 \%$ of those who lived in Gyeonggi-do, $50.0 \%$ of those who lived in Chungcheong-do, and $100.0 \%$ of those who lived in Gangwon-do answered that they wanted to participate once a week, 120 minutes per session, a total of 8 sessions, and $50.0 \%$ of those who lived in Jeolla-do wanted to participate once a week, 120 minutes per session, a total of 12 sessions.

\section{Necessity for forest therapy programs for subfertile couples}

To the question about the necessity for forest therapy programs for subfertile couples, $53.8 \%$ answered no, and $46.2 \%$ answered yes (Table 7), which needs to be compared with the result that the number of those who wanted to participate with spouse was the highest. These results can be attributed to the fact that the existence of spouses has two conflicting sides, that is, support and conflict, which can result in ambivalence (Hwang, 1998; Hwang, 2011; Kim, 2012; Park, 1995). The results differed depending on the age of spouses $(p=.043)$, and $55.8 \%$ of those aged 40 or older answered yes, and $100 \%$ of those aged between 20 and 29 answered no (Table 10). 
Table 9. Duration of forest therapy program for subfertile women by religion and residence

\begin{tabular}{|c|c|c|c|c|c|c|c|c|}
\hline \multirow{2}{*}{ Category } & \multicolumn{7}{|c|}{ Frequency $(\%)$} & \multirow{2}{*}{$\chi^{2}(p)$} \\
\hline & I & II & III & IV & V & VI & Total & \\
\hline \multicolumn{9}{|l|}{ Religion } \\
\hline None & $58(64.4)$ & 17(18.9) & $1(1.1)$ & $3(3.3)$ & $1(1.1)$ & $10(11.1)$ & $90(100.0)$ & \multirow{6}{*}{$\begin{array}{c}41.828 \\
\left(.003^{* *}\right)\end{array}$} \\
\hline Christian & $27(55.1)$ & $13(26.5)$ & $2(4.1)$ & $3(6.1)$ & $0(0)$ & $4(8.2)$ & $49(100.0)$ & \\
\hline Catholic & $18(62.1)$ & $7(24.1)$ & $1(3.4)$ & $0(0)$ & $0(0)$ & $3(10.3)$ & $29(100.0)$ & \\
\hline Buddhism & $18(64.3)$ & $8(28.6)$ & $1(3.6)$ & $1(3.6)$ & $0(0)$ & $0(0)$ & $28(100.0)$ & \\
\hline Others & $2(66.7)$ & $0(0)$ & $0(0)$ & $0(0)$ & $1(33.3)$ & $0(0)$ & $3(100.0)$ & \\
\hline Total & $123(61.8)$ & $45(22.6)$ & $5(2.5)$ & $7(3.5)$ & $2(1.0)$ & $17(8.5)$ & $199(100.0)$ & \\
\hline \multicolumn{9}{|l|}{ Residence } \\
\hline Seoul & $87(60.4)$ & $32(22.2)$ & $3(2.1)$ & $6(4.2)$ & $0(0)$ & $16(11.1)$ & $144(100.0)$ & \multirow{6}{*}{$\begin{array}{l}41.869 \\
(.019 *)\end{array}$} \\
\hline Gyeonggi-do & $25(67.6)$ & $9(24.3)$ & $2(5.4)$ & $0(0)$ & $1(2.7)$ & $0(0)$ & $37(100.0)$ & \\
\hline Chungcheong-do & $2(50.0)$ & $1(25.0)$ & $0(0)$ & $0(0)$ & $1(25.0)$ & $0(0)$ & $4(100.0)$ & \\
\hline Kyongsang & $6(75.0)$ & $1(12.5)$ & $0(0)$ & $1(12.5)$ & $0(0)$ & $0(0)$ & $8(100.0)$ & \\
\hline Jeolla-do & $1(25.0)$ & $2(50.0)$ & $0(0)$ & $0(0)$ & $0(0)$ & $1(25.0)$ & $4(100.0)$ & \\
\hline Gangwon-do & $2(100.0)$ & $0(0)$ & $0(0)$ & $0(0)$ & $0(0)$ & $0(0)$ & $2(100.0)$ & \\
\hline Total & $123(61.8)$ & $45(22.6)$ & $5(2.5)$ & $7(3.5)$ & $2(1.0)$ & $17(8.5)$ & $199(100.0)$ & \\
\hline
\end{tabular}

Note. I = once a week, 120 minutes per session, a total of 8 sessions; $\Pi=$ once a week, 120 minutes per session, a total of 12 sessions; $I I I=$ once a week, 180 minutes per session, a total of 12 sessions; $\mathrm{V}=$ twice a week, 120 minutes per session, a total of 16 sessions; $V=$ twice a week, 180 minutes per session, a total of 16 sessions; $\mathrm{VI}=$ others.

${ }^{*} p<.05,{ }^{* *} p<.01$ by Chi square test.

Table 10. Necessity for forest therapy program for subfertile couples by age of spouse and marriage duration

\begin{tabular}{|c|c|c|c|c|}
\hline \multirow{2}{*}{ Category } & \multicolumn{3}{|c|}{ Frequency $(\%)$} & \multirow{2}{*}{$\chi^{2}(p)$} \\
\hline & Yes & No & Total & \\
\hline \multicolumn{5}{|l|}{ Spouse age } \\
\hline 20-29 years & $0(0)$ & $4(100.0)$ & $4(100.0)$ & \multirow{5}{*}{$\begin{array}{c}8.171 \\
\left(.043^{*}\right)\end{array}$} \\
\hline $30-34$ years & $14(38.9)$ & $22(61.1)$ & $36(100.0)$ & \\
\hline $35-39$ years & $30(41.1)$ & $43(58.9)$ & $73(100.0)$ & \\
\hline Over 40 & $48(55.8)$ & $38(44.2)$ & $86(100.0)$ & \\
\hline Total & $92(46.2)$ & $107(53.8)$ & $199(100.0)$ & \\
\hline \multicolumn{5}{|l|}{ Marriage duration } \\
\hline Less than 1 year & $2(22.2)$ & $7(77.8)$ & $9(100.0)$ & \multirow{7}{*}{$\begin{array}{l}11.093 \\
\left(.050^{*}\right)\end{array}$} \\
\hline $1-2$ years & $14(37.8)$ & $23(62.2)$ & $37(100.0)$ & \\
\hline $2-3$ years & $17(47.2)$ & $19(52.8)$ & $36(100.0)$ & \\
\hline $3-5$ years & $19(37.3)$ & $32(62.7)$ & $51(100.0)$ & \\
\hline $5-10$ years & $33(63.5)$ & $19(36.5)$ & $52(100.0)$ & \\
\hline More than 10 years & $7(50.0)$ & $7(50.0)$ & $14(100.0)$ & \\
\hline Total & $92(46.2)$ & $107(53.8)$ & $199(100.0)$ & \\
\hline
\end{tabular}

${ }^{*} p<.05$ by Chi square test. 


\section{Desired operation hours of forest therapy programs for subfertile couples}

To the question about desired operation hours of forest therapy programs for subfertile couples, the number of those who answered half a day (morning or afternoon) was the highest (38.7\%), followed by a day (19.6\%), and two days and one night (14.6\%), which was similar to the results of Park and Koo (2018) that the number of those who answered a day for forest therapy programs was the highest (Table 8). To the same question, out of 147 women who lived with their spouse only, $52.4 \%$ answered that they intended to participate in a half-day forest therapy program (Table 11), and $50.0 \%$ of those who lived with their parents together answered that they intended to participate in an one-day forest therapy program. It was found that $100 \%$ of those who lived with their husband's siblings answered that they intended to participate in an one-night program.

\section{Qualifications for forest therapists}

As qualifications for forest therapists, subjects selected a deep understanding of symptoms of and women with subfertility (65.3\%), and an understanding of stress and coping methods (19.1\%) (Table 12), which coincided with the results of the report of the Ministry of Health and Welfare (2016) that understanding and sympathy are the basic ele- ments of and qualifications for psychology counseling. The results on qualifications for forest therapists differed depending on the occupation and birth order of spouses (Table 13), and $100 \%$ of those whose spouses were unemployed answered a deep understanding of symptoms of and women with subfertility. Out of those whose spouses were service workers, 55.6\% answered an understanding of stress and coping methods, and $69.6 \%$ of office workers, $56.3 \%$ of self-employed/sales workers, $70.0 \%$ of technical workers, and $64.3 \%$ of professional workers answered a deep understanding of symptoms of and women with subfertility as a top qualification $(p=0.036)$. In other words, all the spouse occupation groups, except service workers, considered a deep understanding of symptoms of and women with subfertility as a top qualification.

\section{Preferred forest types and locations for forest therapy programs}

Forest types preferred by subjects were dense forest (24.1\%) and forest with a good view of surroundings (33.2\%), and $42.7 \%$ answered that they wanted to experience both (Table 14). Natural recreation forest was selected as the most preferred location for forest therapy programs $(46 \%)$, followed by healing forest $(43.9 \%)$, urban forest $(5.0 \%)$, park $(4.0 \%)$, and school forest $(1.0 \%)$, which was similar

Table 11. Desired duration of forest therapy program for subfertile couples by family member living together

\begin{tabular}{lcccccccc}
\hline \multirow{2}{*}{ Category } & \multicolumn{7}{c}{ Frequency(\%) } \\
\cline { 2 - 6 } & Half day & A day & 1 night & 2 nights & 3 nights & Less than a week & Total & $\chi^{2}(p)$ \\
\hline Spouse only & $77(52.4)$ & $38(25.9)$ & $28(19.0)$ & $2(1.4)$ & $0(0)$ & $2(1.4)$ & $147(100.0)$ \\
Parents & $0(0)$ & $1(50.0)$ & $0(0)$ & $0(0)$ & $1(50.0)$ & $0(0)$ & $2(100.0)$ & 80.116 \\
Spouse's sibling & $0(0)$ & $0(0)$ & $1(100.0)$ & $0(0)$ & $0(0)$ & $0(0)$ & $1(100.0)$ & $\left(.000^{* * *}\right)$ \\
Total & $77(51.3)$ & $39(26.0)$ & $29(19.3)$ & $2(1.3)$ & $1(0.7)$ & $2(1.3)$ & $150(100.0)$ & \\
\hline
\end{tabular}

$* * * p<.001$ by Chi square test.

Table 12. Most important qualification of forest therapist for subfertile women $(\mathrm{N}=199)$

\begin{tabular}{lrr}
\hline \multicolumn{1}{c}{ Category } & $\mathrm{n}$ & $\%$ \\
\hline A deep understanding and sympathy for the symptoms & 125 & 64.4 \\
Insights and philosophies about the attitudes of religion and subjective life & 16 & 8.2 \\
Understanding of stress and coping methods & 38 & 19.6 \\
Ability of program operation by group and individual & 3 & 1.5 \\
Guidance on the mechanism of body / psychology (connection of body and mind) & 12 \\
\hline
\end{tabular}


to the results of Kim (2015) that people preferred dense and thick forest, forest with a good view of surroundings, natural creation forest, and healing forest. In terms of the types of spaces for programs, 33.7\% answered that any types of spaces available are fine (33.7\%), followed by cozy spaces surrounded by trees $(33.2 \%)$, open spaces with grass unfolded in all directions (20.1\%), and spaces with wooden decks where a meditation mat can be spread (13.1\%).

The results on the preferred locations for forest therapy programs differed depending on the residence of subjects (Table 15). Out of those who lived in Seoul, 46.5\% answered they preferred natural recreation forest, and $43.2 \%$ of those who lived in Gyeonggi-do preferred healing forest and natural recreation forest respectively. Out of those who lived in Chungcheong-do, $75.0 \%$ preferred healing forest, and $75.0 \%$ of those who lived in Gyeongsang-do preferred natural recreation forest. In addition, $50.0 \%$ of those who lived in Joella-do answered healing forest and natural recreation forest respectively, and $50.0 \%$ of those who lived in Gangwon-do answered school forest and natural recreation forest respectively.

\section{Expected physical effects of forest therapy programs}

To the question about forest therapy factors that are expected to be helpful for subfertile women, the share of phytoncide was the highest $(36.2 \%)$, followed by a high level of oxygen $(30.2 \%)$, and sunshine $(20.6 \%)$. As expected

Table 13. Qualification of forest therapist for subfertile women by occupation of spouse

\begin{tabular}{lccccccc}
\hline \multirow{2}{*}{ Category } & \multicolumn{7}{c}{ Frequency $(\%)$} \\
\cline { 2 - 6 } & $\mathrm{I}$ & $\mathrm{I}$ & $\mathrm{II}$ & $\mathrm{IV}$ & $\mathrm{V}$ & Total & $\chi^{2}(p)$ \\
\hline Unemployed & $3(100.0)$ & $0(0)$ & $0(0)$ & $0(0)$ & $0(0)$ & $3(100.0)$ \\
Service & $4(44.4)$ & $0(0)$ & $5(55.6)$ & $0(0)$ & $0(0)$ & $9(100.0)$ \\
Office worker & $48(69.6)$ & $6(8.7)$ & $11(15.9)$ & $0(0)$ & $4(5.8)$ & $69(100.0)$ & 32.720 \\
Self-employed / Sales & $18(56.3)$ & $1(3.1)$ & $8(25.0)$ & $3(9.4)$ & $2(6.3)$ & $32(100.0)$ & $\left(.036^{*}\right)$ \\
Technical & $21(70.0)$ & $1(3.3)$ & $5(16.7)$ & $0(0)$ & $3(10.0)$ & $30(100.0)$ & $56(100.0)$ \\
Professional & $36(64.3)$ & $8(14.3)$ & $9(16.1)$ & $0(0)$ & $3(5.4)$ & $12(6.0)$ & $199(100.0)$ \\
Total & $130(65.3)$ & $16(8.0)$ & $38(19.1)$ & $3(1.5)$ & \\
\hline
\end{tabular}

Note. $I=$ a deep understanding and sympathy for the symptoms; $I=$ insights and philosophies about the attitudes of religion and subjective life; $I I=$ understanding of stress and coping methods; $I=$ ability of program operation by group and individual; $V=$ guidance on the mechanism of body / psychology (connection of body and mind).

$* p<.05$ by Chi square test.

Table 14. Preferred forest type and location for forest therapy program for subfertile women $(\mathrm{N}=199)$

\begin{tabular}{|c|c|c|c|}
\hline Variable & Category & $\mathrm{n}$ & $\%$ \\
\hline \multirow[t]{3}{*}{ Forest type } & Dense forest & 48 & 24.1 \\
\hline & Forest with a good view of the surroundings & 66 & 33.2 \\
\hline & Both & 85 & 42.7 \\
\hline \multirow[t]{5}{*}{ Forest location } & Urban forest & 10 & 5.0 \\
\hline & School forest & 2 & 1.0 \\
\hline & Park & 8 & 4.0 \\
\hline & Healing forest & 87 & 43.7 \\
\hline & Natural recreation forest & 92 & 46.2 \\
\hline \multirow[t]{4}{*}{ Type of space in forest } & A cozy space surrounded by wood & 65 & 33.2 \\
\hline & Open space with grass unfolded in all directions & 40 & 20.1 \\
\hline & Space with wooden decks for meditation & 26 & 13.1 \\
\hline & Various types of spaces & 67 & 33.7 \\
\hline
\end{tabular}


physical effects, the share of blood circulation was the highest (49.2\%), followed by quality sleep (16.1\%) and strengthened immunity (16.1\%). As expected psychological effects, the share of meditation opportunity was the highest $(40.2 \%)$, followed by tranquility in forests $(26.6 \%)$, a sense of freedom/escape (18.1\%) and self-reflection opportunity $(12.1 \%)$. As the effects of self-help groups in forest therapy programs for subfertile women, the share of improving physical and mental health through shared activities was the highest (41.2\%), followed by sympathy based on a common issue called subfertility (28.6\%), making friendships and groups to share feelings (14.6\%), and exchanging various information on pregnancy (13.1\%, Table 16). These results were very similar to the results of Kim (2015). It was found that the effects of forest therapy expected by subfertile women and the expected effects of forest therapy reported by earlier studies were similar. These results indicate that several effects can be expected from forest therapy programs for improving the physical and mental health of subfertile women. The results on expected physical effects differed depending on the age of subjects and number of family members (Table 17). Those aged between 20 and 29 answered reduced symptoms of cold hands and feet, and cold stomach (28.6\%), and quality sleep (28.6\%), and $51.7 \%$ of those aged between 30 and $34,53.2 \%$ of those aged between 35 and 39 , and $45.5 \%$ of those aged 40 or older answered blood circulation ( $p=.041)$. In other words, those aged between 20 and 29 expected that forest therapy

Table 15. Preferred forest location for forest therapy program for subfertile women by residence

\begin{tabular}{lccccccc}
\hline \multirow{2}{*}{ Category } & \multicolumn{7}{c}{ Frequency $(\%)$} \\
\cline { 2 - 6 } & Urban forest & School forest & Park & Healing forest & Natural recreation forest & Total & $\chi^{2}(p)$ \\
\hline Seoul & $5(3.5)$ & $1(0.7)$ & $7(4.9)$ & $64(44.4)$ & $67(46.5)$ & $144(100.0)$ \\
Gyeonggi-do & $4(10.8)$ & $0(0)$ & $1(2.7)$ & $16(43.2)$ & $16(43.2)$ & $37(100.0)$ \\
Chungcheong-do & $1(25.0)$ & $0(0)$ & $0(0)$ & $3(75.0)$ & $0(0)$ & $4(100.0)$ & 62.453 \\
Gyeongsang-do & $0(0)$ & $0(0)$ & $0(0)$ & $2(25.0)$ & $6(75.0)$ & $8(100.0)$ & $\left(.000^{* * *}\right)$ \\
Jeolla-do & $0(0)$ & $0(0)$ & $0(0)$ & $2(50.0)$ & $2(50.0)$ & $4(100.0)$ & $2(100.0)$ \\
Gangwon-do & $0(0)$ & $1(50.0)$ & $0(0)$ & $0(0)$ & $1(50.0)$ & $199(100.0)$ \\
Total & $10(5.0)$ & $2(1.0)$ & $8(4.0)$ & $87(43.7)$ & $9(46.2)$ & \\
\hline
\end{tabular}

$* * * p<.001$ by Chi square test.

Table 16. Expected effects of forest therapy program for subfertile women $(N=199)$

\begin{tabular}{|c|c|c|c|}
\hline Variable & Category & $\mathrm{n}$ & $\%$ \\
\hline \multirow[t]{3}{*}{ Therapy factor in forest } & Fresh air & 60 & 30.2 \\
\hline & Moderate sunshine & 41 & 20.6 \\
\hline & Phytoncide & 72 & 36.2 \\
\hline \multirow[t]{3}{*}{ Expected physical effects } & Blood circulation & 98 & 49.2 \\
\hline & Strengthened immunity & 32 & 16.1 \\
\hline & Quality sleep & 32 & 16.1 \\
\hline \multirow[t]{4}{*}{ Expected psychological effects } & Meditation opportunity & 80 & 40.2 \\
\hline & Self-reflection opportunity & 24 & 12.1 \\
\hline & Tranquility in the forest & 53 & 26.6 \\
\hline & Sense of freedom / escape & 36 & 18.1 \\
\hline \multirow[t]{4}{*}{ Effects of self-help groups } & Empathy based on a common issue & 57 & 28.6 \\
\hline & Improving physical and mental health through shared activities & 82 & 41.2 \\
\hline & Exchange of various information for pregnancy & 26 & 13.1 \\
\hline & Making friendships to share feelings & 29 & 14.6 \\
\hline
\end{tabular}


Table 17. Expected physical effects in forest therapy programs for subfertile women by age and family member living together

\begin{tabular}{|c|c|c|c|c|c|c|c|c|c|c|}
\hline \multirow{2}{*}{ Category } & \multicolumn{9}{|c|}{ Frequency $(\%)$} & \multirow{2}{*}{$\chi^{2}(p)$} \\
\hline & I & II & III & IV & $\mathrm{V}$ & $\mathrm{VI}$ & VII & VIIII & Sum & \\
\hline \multicolumn{11}{|l|}{ Age } \\
\hline 20-29 years & $0(0)$ & $1(14.3)$ & $1(14.3)$ & $2(28.6)$ & $0(0)$ & $0(0)$ & $1(14.3)$ & $2(28.6)$ & $7(100.0)$ & \multirow{5}{*}{$\begin{array}{l}33.484 \\
\left(.041^{*}\right)\end{array}$} \\
\hline $30-34$ years & $3(5.2)$ & $30(51.7)$ & $3(5.2)$ & $4(6.9)$ & $8(13.8)$ & $0(0)$ & $2(3.4)$ & $8(13.8)$ & $58(100.0)$ & \\
\hline $35-39$ years & $4(5.1)$ & $42(53.2)$ & $2(2.5)$ & $5(6.3)$ & $7(8.9)$ & $2(2.5)$ & $3(3.8)$ & 14(17.7) & $79(100.0)$ & \\
\hline Over 40 & $2(3.6)$ & $25(45.5)$ & $0(0)$ & $3(5.5)$ & $17(30.9)$ & $0(0)$ & $0(0)$ & $8(14.5)$ & $55(100.0)$ & \\
\hline Total & $9(4.5)$ & $98(49.2)$ & $6(3.0)$ & $14(7.0)$ & $32(16.1)$ & $2(1.0)$ & $6(3.0)$ & $32(16.1)$ & $199(100.0)$ & \\
\hline \multicolumn{11}{|c|}{ Family member living together } \\
\hline Spouse only & $7(3.7)$ & $94(49.2)$ & $6(3.1)$ & $14(7.3)$ & $31(16.2)$ & $2(1.0)$ & $5(2.6)$ & $32(16.8)$ & $199(100.0)$ & \multirow{4}{*}{$\begin{array}{c}46.525 \\
(.001 * * *)\end{array}$} \\
\hline Parents & $2(33.3)$ & $3(50.0)$ & $0(0)$ & $0(0)$ & $1(16.7)$ & $0(0)$ & $0(0)$ & $0(0)$ & $6(100.0)$ & \\
\hline Parents-in-law & $0(0)$ & $1(100.0)$ & $0(0)$ & $0(0)$ & $0(0)$ & $0(0)$ & $0(0)$ & $0(0)$ & $1(100.0)$ & \\
\hline Spouse's sibling & $0(0)$ & $0(0)$ & $0(0)$ & $0(0)$ & $0(0)$ & $0(0)$ & $1(100.0)$ & $0(0)$ & $1(100.0)$ & \\
\hline Total & $9(4.5)$ & $98(49.2)$ & $9(3.0)$ & $14(7.0)$ & $32(16.1)$ & $2(1.0)$ & $6(3.0)$ & $32(16.1)$ & $199(100.0)$ & \\
\hline
\end{tabular}

Note. I = muscle strengthening; $I=$ blood circulation; $\mathrm{II}=$ pelvic exercise; $\mathrm{IV}=$ reduced symptoms of cold hands, feet, and stomach; $\mathrm{V}=$ strengthened immunity; VI= exercise for digestive health; VII = body fat loss; VIII = quality sleep.

${ }^{*} p<.05,{ }^{* * *} p<.001$ by Chi square test.

programs reduce symptoms of cold hands and feet and cold stomach, and provide quality sleep, and those aged 30 or older expected that the programs improve blood circulation. In addition, $49.2 \%$ of those who lived with their spouse only, $50.0 \%$ of those who lived with their parents together, and $100.0 \%$ of those who lived with their parents-in-law together answered blood circulation, and $100 \%$ of those who lived with their spouse's siblings together answered body fat loss $(p=.001)$.

\section{Conclusion}

In this study, a survey was conducted on 199 women who visited a fertility clinic in Seoul, and their interest in and needs for forest therapy programs were surveyed based on their demographic characteristics in order to provide basic data for developing and executing forest therapy programs for the physical and mental health of subfertile women. The following results were reached. First, subfertile women's awareness and experience of forest therapy were both low, but they were found to be positive about participating in the programs. Second, they were found to prefer to participate in a small-group program for a half day during weekends with their spouse. Third, therapeutic factors that subfertile women expected from forest therapy programs included phytoncide (35.8\%) and a high level of oxygen (29.9\%). Fourth, subfertile women were found to expect from forest therapy programs physical and mental health such as improved blood circulation and immunity, and meditation opportunity. Fifth, they expected the most an understanding and sympathy of subfertility from forest therapists (62.2\%). Since this study conducted a survey on 199 subfertile women only, it is difficult to generalize the results of this study. It will be necessary to conduct a follow-up study on a larger number of subfertile women in a broader region, which is expected to lead to more effective forest therapy programs for promoting the physical and mental health of subfertile women.

\section{References}

Chang, C.Y. and P.K. Chen. 2005. Human response to window views and indoor plants in the workplace. HortScience 40(5):1354-1359. https://doi.org/10.21273/HORTSCI.40.5.1354

Cousineau, T.M. and A.D. Domar, 2007. Psychological im- 
pact of infertility. Best Pract. Res. Clin. Obstet. Gynaecol. 21(2):293-308. https://doi.org/10.1016/j.bpobgyn.2006.12.003

Devine, K.S. 2003. Caring for the infertile women. MCN Am. J. Matern. Child Nurs. 28(2):100-105.

Domar, A.D., P.C. Zuttermeister, and R. Friedman. 1993. The psychological impact of Infertility: A comparison with patients with other medical conditions. J. Psychosom. Obstet. Gynaecol. 14(Suppl):45-52.

Hartig, T., M. Mang, and G.W. Evans. 1991. Restorative effects of natural environment experiences. Environ. Behav. 23(1):3-26. https://doi.org/10.1177/0013916591231001

Hwang, N. 2011. Physical, mental, and socioeconomic burden status and needs of infertility treatment for infertile women. Health Welfare Issue Focus [Korea Institute for Health and Social Affairs] 74(6):1-8.

Hwang, N, S.M. Chae, S.L. Lee, Y.S. Kim, J.K. Kim, and J.W. Jeon. 2015. Strategies of infertility counseling program of industrialized countries and policy implication in Korea (Report No. 2015-03). Seoul, Korea: Korea Institute for Health and Social Affairs.

Hwang, S.S. 1998. Analysis of conceptual meaning of female infertility. Hanyang Univ. Nurs. Res. 3(2):2-11.

Kang, E.Y. 2015. Cognitive behavioral therapy for psychosocial adjustment of infertile women. Doctoral dissertation, Myongji University, Seoul, Korea.

Kim, K.W. 2006. Theoretical study of characteristics of therapeutic elements and application to forest therapy. J. Korean Soc. People Plants Environ. 9(4):111-123.

Kim, O.S. 2012. A phenomenological study on adoptive experience of infertile women. Fam. Couns. [Soongsil University] 2(2):49-73.

Kim, R.H., W.N. Lee, Y.J. Kim, Y.M. Sung, J.K. Hoh, D.W. Han, Y.M. Choi, and J.H. Hwang. 2011. Current status of imfertility counseling in Korea. Korean $\mathrm{J}$. Obstet. Gynecol. 54(10):611-617. https://doi.org/10.54 68/KJOG.2011.54.10.611

Kim, Y.H. 2015. The analysis of needs for the development of forest therapy program. Doctoral dissertation, Chungbuk National University, Cheongju, Korea.

Kim, Y.H., D.J. Kim, P.S. Yeoun, and B.J. Choi. 2014. The analysis of interests and needs for the develop- ment of forest therapy program in adults. J. Korean Inst. For. Recreat. 18(3):45-59.

Lee, B.G. and H.H. Lee. 2013. Effects of occupational and social stresses after forest therapy. J. Naturopathy 2(2):108-114.

Lee, Y.H. and K.W. Kim. 2011. Visitors'behavior and needs of national recreational forests in Korea. J. Korean Soc. People Plants Environ. 14(4):245-252.

Lee, S.H. 2007. The effects of the index of greenness simulation based on restorative environment model upon emotion improvement. Korean J. Health Psychol. 12(2):439-465.

Lindsey, B. and C. Driskill. 2013. The psychology of infertility. Int. J. Childbirth Educ. 28(3):41-47.

Maller, C., M. Townsend, A. Pryor, P. Brown, and L. St Leger. 2006. Healthy nature healthy people:'contact with nature' as an upstream health promotion intervention for populations. Health Promot. Int. 21(1):45-54.

Miles, L.M. 2005. Predictor of distress in women being treated for infertility. Doctoral dissertation, Fordham University, New York, USA.

Ministry of Health and Welfare. 2016. Research on the status of infertility counseling and provision of counseling services (Report No. 11-1352000-001853-01). Seoul, Korea: Author.

Park, B.J. 2010. Experimental approach of therapeutic effect of forest recreation activities: Focused on viewing and walking in forest environments. Doctoral dissertation, Chungnam National University, Daejeon, Korea.

Park, S.H. and C.D. Koo. 2018. Needs analysis for the development of forest therapy program utilizing the urban forest: Focused on the visitors of Incheon Grand Park. J. Korean Inst. For. Recreat. 22(1):11-24. https://doi.org/10.34272/forest.2018.22.1.002

Park, Y.J. 1993. A study on the experience of infertility: Focusing on the women who visited the fertility clinic. Doctoral dissertation, Yonsei University, Seoul, Korea.

Park, Y.J. 1995. The stress of the infertile women. J. Korean Acad. Womens Health Nurs. 1(2):209-221.

Peterson, B.D., L. Gold, and T. Feingold. 2007. The experience and influence of infertility: Consideration for 
couple counselors. Family J. 15(3):251-257.

https://doi.org/10.1177/1066480707301365

Seok, H.D. and S.J. An. 2013. Policy of forest environmental service for happiness. Naju, Korea: Korea Rural Economic Institute.

Tsunetsugu, Y., B.J. Park, H. Ishii, H. Hirano, T. Kagawa, and Y. Miyazaki. 2007. Physiological effects of shinrin-yoku (taking in the atmosphere of the forest) in an old-growth broadleaf forest in Yamagata Prefecture, Japan. J. Physiol. Anthropol. 26(2):135-142.

Ulrich, R.S., R.F. Simons, B.D. Losito, E. Fiorito, M.A. Miles, and M. Zelson. 1991. Stress recovery during exposure to natural and urban environments. J. Environ. Psychol. 11(3):201-230.

https://doi.org/10.1016/S0272-4944(05)80184-7

Van Den Berg, A.E. and M.H. Custers. 2011. Gardening promotes neuroendocrine and affective restoration from stress. J. Health Psychol. 16(1):3-11. https://doi.o rg/10.1177/135910531036557

Woo, J.M. 2014. Stress and Health. In: Forest healing instructor Class 1 Materials (pp. 8-30). Daejeon, Korea: Korea Forest Service.

Yong, P., C. Martin, and J. Thong. 2000. A comparison of psychological functioning in women at different stages of invitro fertilization treatment using the mean affect adjective check list. J. Assist. Reprod. Genet. 17(10):553-556.

Yoo, R.H. and S.Y. Jeong. 2009. A case study on application of the effect using forest on human health improvement and disease prevention: Focusing on the forest therapy certification in Japan. J. Korean Inst. For. Recreat. 13(2):45-51. 